\title{
O conhecimento tácito e a subjetividade do professor de Educação Física Escolar
}

\author{
Tacit knowledge and subjectivity of the School Physical Education teacher
}

Conocimiento tácito y subjetividad del profesor de Educación Física Escolar

\author{
Jorge Adilson Gondim Pereira ${ }^{\mathrm{i}}$ \\ Antônia Vitória Soares Aranha ${ }^{\mathrm{ii}}$
}

\begin{abstract}
Resumo: Este estudo analisa o conhecimento tácito no trabalho docente da Educação Física Escolar. A divergência entre o prescrito e o real permite ao professor renormalizar, criar estratégias e saberes tendo como suporte os conhecimentos tácitos. Trata-se de uma pesquisa qualitativa com dois professores de escolas públicas estaduais e municipais da Bahia. Os resultados demonstram que os professores de Educação Física utilizam mais o conhecimento tácito em virtude da ausência de prescrições e do incipiente acompanhamento pedagógico.
\end{abstract}

Abstract: This study analyzes the tacit knowledge in the teaching work of School Physical Education. The divergence between the prescribed and the real allows the teacher to renormalize, create strategies and knowledge based on tacit knowledge. This is a qualitative research with two teachers from state and municipal public schools in Bahia. The results show that Physical Education teachers use tacit knowledge more due to the absence of prescriptions and the incipient pedagogical monitoring.

Resumen: Este estudio analiza el conocimiento tácito en el trabajo docente de la Educación Física Escolar. La divergencia entre lo prescrito y lo real le permite al maestro renormalizar, crear estrategias y conocimientos basados en el conocimiento tácito. Esta es una investigación cualitativa con dos maestros de escuelas públicas estatales y municipales en Bahía. Los resultados muestran que los maestros de Educación Física utilizan más el conocimiento tácito debido a la ausencia de recetas y al incipiente monitoreo pedagógico.

Palavras-chave: Conhecimento tácito; Educação Física Escolar; Trabalho docente.

Keywords: Conocimiento tácito; Educación física escolar; Trabajo docente

Palabras claves: Tacit knowledge; School Physical Education; Teaching work. 


\section{INTRODUÇÃO}

O nosso objeto de estudo, encontra-se imerso no trabalho docente em Educação Física, embora não seja exclusividade desse campo. Neste estudo, nos ocupamos de um universo complexo e enigmático chamado trabalho que, perpassado por normas e pela produtividade, impõe um drama ao ser humano que trabalha.

A noção de trabalho que trazemos é fruto de um intenso diálogo entre as acepções marxianas e as abordagens clínicas do trabalho, em especial a ergonomia e a ergologia.

Marx (1994) em “O Capital”, assevera que o ato de viver coloca o ser humano frente a vários obstáculos, intempéries, dificuldades que o faz reagir, usar a sua consciência e a sua inteligência para superá-los. Para tanto, o ser humano reúne todo o seu arsenal de conhecimento anterior criando, nesta ação, novas estratégias e conhecimentos ao mesmo tempo que se transforma.

Porém, na sociedade burguesa, esse mesmo trabalho subordina-se aos interesses daqueles que dominam os meios de produção. O trabalhador, é convertido em mercadoria vendendo a sua força de trabalho em troca da sua sobrevivência. Nestas condições, o trabalho se torna alienado ${ }^{1}$ na medida em que o trabalhador é subsumido à lógica capitalista de produção. A divisão social do trabalho também corrobora com o trabalho alienado colocando em lados opostos conceptor e executor.

Em outra perspectiva de análise, busca-se avançar na compreensão do microcosmo do trabalho. É na atividade de trabalho ${ }^{2}$ que se procura captar as nuances da ação humana evidenciando que, mesmo em condições de exploração, o ser humano é capaz de reagir produzindo saberes alternativos àqueles que lhe são determinados. O ser humano, na atividade de trabalho, atua com um repertório de conhecimentos e saberes oriundos de dois campos como se segue: os saberes constituídos e os saberes investidos. Os saberes constituídos são compostos por um patrimônio cultural que se encontra devidamente registrado e socializado entre as pessoas. Por outro lado, os trabalhadores operam com outro tipo de saber que são os saberes investidos. Estes saberes são intangíveis, não codificáveis, singulares e, portanto, de domínio pessoal. São produzidos na emergência do trabalho e tem como suporte os saberes da experiência. Seu propósito é preencher as lacunas existentes entre aquilo que se planeja e aquilo que se executa realmente. É nesse vazio de normas que emerge a categoria essencial do nosso estudo, o conhecimento tácito ${ }^{3}$ no trabalho docente da Educação Física.

\footnotetext{
1 (...) o objeto produzido pelo trabalho, o seu produto, se lhe opõe como ser estranho, como um poder independente do produtor. O produto do trabalho é o trabalho que se fixou num objeto, que se transformou em coisa física, é a objetivação do trabalho. A realização do trabalho constitui simultaneamente a sua objetivação. A realização do trabalho aparece na esfera da economia política como desrealização do trabalhador, a objetivação como perda e servidão do objeto, a apropriação como alienação. (Marx, 1964, p. 159).

2 A partir das reflexões de Wisner (1972; 1982; 1987; 1995), Schwartz (2000a; 2004; 2009) incorporou e desenvolveu o conceito de "atividade" originário da ergonomia, mostrando que a ergologia assim como a ergonomia busca melhor conhecer e intervir sobre as situações de trabalho para transformá-las. O conceito de atividade, para a ergonomia, encontra-se fortemente ligado ao seu caráter imprevisível, uma vez que requer a inteligência criadora dos trabalhadores. (FERREIRA, 2008).

3 Tácito tem origem na palavra tacere (calar), por conseguinte o saber tácito é aquele que não se encontra expresso em palavras, podendo, no entanto, ser demonstrado e compartilhado por meio de outros códigos de
} 
De modo preliminar, podemos nos referir a ele como um conhecimento extraído das nossas experiências de vida e que utilizamos para preencher as lacunas existentes entre aquilo que planejamos e o que realmente executamos. Para Aranha,

"O conhecimento tácito é parte integrante e importante da qualificação do trabalhador. E mais, que o trabalhador, ainda que de forma assistemática, produz conhecimento, elabora um saber sobre o trabalho, que não é apenas constituído de noções de sobrevivência e relacionamento na selva competitiva do mercado de trabalho, mas que é também técnico" (1997:19)

Diante disto perguntamos: Como o conhecimento tácito contribui para a expressão da subjetividade do professor na Educação Física Escolar?

Além disso, apresentamos outras questões norteadoras: Como se processa a divergência entre trabalho prescrito/abstrato e trabalho real/concreto na Educação Física? Como se dão os usos do corpo-si no trabalho docente do professor de Educação Física? Como são produzidos e constituídos os conhecimentos tácitos nas aulas de Educação Física. Qual a relação entre os conhecimentos produzidos na formação inicial e aqueles produzidos ao longo do trabalho docente da Educação Física? Qual a relação entre os saberes tácitos e saberes teóricos no trabalho docente da Educação Física? Qual o sentido e o significado da competência na docência em Educação Física?

\section{Objetivo Geral:}

Analisar a importância do conhecimento tácito no trabalho docente da Educação Física Escolar

\section{Objetivos Específicos:}

Descrever o processo de divergência entre trabalho prescrito e trabalho real na Educação Física;

$>$ Avaliar os usos do corpo-si no trabalho docente do professor de Educação Física;

$>$ Identificar como são produzidos e constituídos os conhecimentos tácitos nas aulas de Educação Física;

> Relacionar os conhecimentos produzidos na formação inicial àqueles produzidos ao longo trabalho docente da Educação Física;

comunicação não verbal. Michael Polanyi desenvolveu, nas décadas de 1950 e 1960, uma série de estudos sobre a dimensão tácita do conhecimento. Partindo da afirmação que sabemos mais do que conseguimos dizer, deu origem a uma influente linha de pensamento sobre a estrutura do conhecimento tácito (SILVA, 2016). 
Refletir sobre a relação entre os saberes tácitos e saberes teóricos no trabalho docente da Educação Física;

Discutir sobre o sentido e o significado da competência na docência em Educação Física.

\section{Metodologia}

\section{TIPO DA PESQUISA/ABORDAGEM}

Em virtude da condição de invisibilidade e subjugação externa do conhecimento tácito, faz-se necessário utilizar estratégias de investigação que consigam não só captar esse fenômeno como também criar condições para que ele emerja em forma de narrativas, especialmente, dos professores, principais agentes educacionais.

Sendo fiel a esses pressupostos, optamos pela pesquisa qualitativa que na visão de Minayo (2001), trabalha com o universo de significados, motivos, aspirações, crenças, valores e atitudes, o que corresponde a um espaço mais profundo das relações, dos processos e dos fenômenos que não podem ser reduzidos à operacionalização de variáveis.

Patton apud Alves-Mazzotti; Gewandsznajder (1999) observa que a pesquisa qualitativa tem como principal característica o princípio de que as pessoas agem em função de suas crenças, percepções, sentimentos e valores e que seu comportamento tem sempre um sentido, um significado que não se dá a conhecer de modo imediato, precisando ser desvelado.

\section{PROCEDimentos / INSTRUMENTOS DE COLETA DE DADOS}

A coleta de dados se deu incialmente por meio da observação e, no decorrer destas, com o auxilio de entrevistas e análise de documentos.

A observação de fatos, comportamentos e cenários é extremamente valorizada pelas pesquisas qualitativas. Essa técnica de pesquisa tem como vantagem o fato de que, independe do nível de conhecimento ou da capacidade verbal dos sujeitos, permite checar, na prática, a sinceridade de certas respostas que, às vezes, são dadas só para causar boa impressão. Além disso, ainda possui outras vantagens como: permite identificar comportamentos não-intencionais ou inconscientes e explorar tópicos que os informantes não se sentem à vontade para discutir; permite o registro do comportamento em seu contexto temporal-espacial. Por fim, as observações podem ser estruturadas ou sistemáticas e não-estruturadas ou assistemáticas (ALVES-MAZZOTTI; GEWANDSZNAJDER, 1999).

Neste estudo, utilizamos a observação não-estruturada ou assistemática em virtude da necessidade de se identificar os sentidos e significados atribuídos a determinados fatos ou ações que são imprevisíveis e incomensuráveis. Os fatos observados foram anotados em diário de bordo ou de campo. O diário é um dispositivo na inves tigação, pelo seu caráter subjetivo, intimista (MACEDO, 2010, p. 134). 
Além da observação, o estudo contou com as entrevistas junto aos professores observados. Rubin e Rubin apud Alves-Mazzotti; Gewandsznajder (1999) descrevem uma variada gama de tipos de entrevistas qualitativas, distinguindo-as pelo grau de controle exercido pelo entrevistador sobre o diálogo. No caso dessa pesquisa foram feitas duas entrevistas. A primeira realizada no início do processo de observação e visa identificar a trajetória de vida do entrevistado em relação à Educação Física. A segunda entrevista aconteceu no final do processo de observação e foram mais focalizadas, quando o entrevistador faz perguntas específicas, mas também deixa que o entrevistado responda em seus próprios termos. Essas entrevistas visam compreender e esclarecer melhor os fatos observados.

Além das entrevistas direcionadas aos professores, fizemos nesse trabalho uma narrativa autobiográfica. Nesta técnica de pesquisa, e, por estar implicado no contex to do trabalho docente da Educação Física Escolar, o pesquisador narrou suas experiências relacionadas com a produção dos conhecimentos tácitos durante o seu percurso profissional.

\section{ANÁLISE DOS DADOS}

Com relação ao desenvolvimento da análise dos dados coletados, será realizado de forma indutiva, pois estes não visam à comprovação ou não de hipótese inicial. As abstrações serão constituídas à medida que os dados coletados forem sendo organizados com vista à sua análise. Para a compreensão do objeto em estudo, será levado em consideração o significado que os professores sujeitos da pesquisa dão às interações que se constituem no processo durante a coleta de dados. Os dados transcritos da observação, entrevistas e documentos serão analisados por meio da técnica de análise de conteúdo e análise do discurso.

\section{RESUlTADOS E DISCUSSÃO}

Depois de termos feito o processo de observação do trabalho docente dos professores de Educação Física nas escolas observamos o seguinte:

- A ausência do material didático induz os professores a estruturarem planejamentos mais conectados com as circunstância e demandas reais do seu espaço de trabalho;

- Os conteúdos selecionados e estratégias de ensino, em geral, estão mais afinados com a experiência do professor e com as expectativas dos alunos, pois, na ausência de um guia prescritivo, as circunstâncias de ensino acabam cumprindo mais ou menos esse papel;

- Com essa estratégia, o professor de Educação Física passa a operar mais com os elementos práticos e sensíveis e menos com as prescrições ou conteúdos teóricos;

- Em virtude destas circunstâncias podemos perceber o quanto o trabalho docente em Educação Física assume uma condição de singularidade frente a outras disciplinas que 
possuem condições mais dignas e regulares de trabalho, além de poderem contar com o material didático. Essa singularidade reside na riqueza e no protagonismo dos professores que criam alternativas, saberes e estratégias capazes de superar os limites interpostos ao desenvolvimento do seu trabalho;

Além das análises anteriores, é importante refletir também sobre as dramáticas dos usos de $\mathrm{si}^{4}$ no trabalho docente em Educação Física. Esse conceito, cunhado por Yves Schwartz, nos remete a como os professores operam em suas aulas tendo como suporte, ora os conhecimentos explícitos quando fazem uso de si a partir de outras pessoas e ora por meio dos conhecimentos tácitos, quando fazem uso de si por si mesmo.

Os professores de Educação Física em virtude da ausência do livro didático, operam com um número reduzido de prescrições. Nesta perspectiva, ao operar mais com os conhecimentos tácitos e a partir da emergência do trabalho, terminam por fazerem mais usos de si mesmos durante a atividade de trabalho do que, possivelmente, os professores de outras áreas.

Ao assumir, supostamente, uma menor representatividade em torno da formação geral dos alunos, a Educação Física tem uma cobrança e acompanhamento diferenciado. O currículo escolar, em virtude da relação de saberes existentes em seu corpus, completamente subsumida à mais valia, à ascensão social burguesa, elege os saberes que darão melhor suporte aos alunos para se adaptarem a lógica de mercado. A Educação Física, dissociada desta lógica, acaba ficando por último no que se refere às cobranças dos órgãos responsáveis pelo cumprimento do que foi planejado, tão pouco é sugerido aquilo que se deve planejar.

Nesse sentido, os professores das disciplinas supostamente mais relevantes operam mais a partir de outrem do que os professores de Educação Física que, além de não seguirem o seu trabalho por meio de um guia, terminam sendo menos cobrados por isso.

\section{CONCLUSÃO}

Este trabalho refere-se à uma pesquisa ainda em andamento, mas, depois das observações e análises realizadas, podemos concluir o seguinte até agora:

- A ausência do material didático induz os professores a estruturarem planejamentos mais conectados com as circunstância e demandas reais do seu espaço de trabalho;

\footnotetext{
4 Trabalhar, segundo Schwartz (2004), envolve se relacionar com as determinações, normas institucionais "gestão do uso de si pelos outros" - e ao mesmo tempo lidar com os julgamentos que cada pessoa concede ao próprio corpo, às próprias capacidades, aos saberes. Schwartz (2004), ainda ressalta que trabalhar significa tomar decisões, confrontar valores diversos, fazer escolhas em alguns momentos contraditórios. O trabalho representa uma "dramática do uso de si”. Para Schwartz (2004), o termo dramático nos remete a uma história à qual não se pode escapar, uma espécie de destino a ser vivido. O autor ainda entende por "dramática" o movimento entre norma prescrita, infidelidade do meio, renormalização e atividade singular ressaltando que a "dramática" é a contradição inerente a toda atividade de trabalho, própria da vida (DURRIVE, 2011, p.47-67).
} 
- Os conteúdos selecionados e estratégias de ensino, em geral, estão mais afinados com a experiência do professor e com as expectativas dos alunos, pois, na ausência de um guia prescritivo, as circunstâncias de ensino acabam cumprindo mais ou menos esse papel;

- Com essa estratégia, o professor de Educação Física passa a operar mais com os elementos práticos e sensíveis e menos com as prescrições ou conteúdos teóricos;

- A incipiência de material didático e a o reduzido acompanhamento docente da área estimulam o professor de Educação Física a fazer o uso de si por si próprio ao contrário de outros professores;

- Por fim, além de existir uma presença marcante de conhecimento tácito no trabalho do professor de Educação Física isso contribui para um trabalho mais rico e de uma expressão mais livre no trabalho por parte desse trabalhador.

\section{REFERÊNCIAS BIBLIOGRÁFICAS}

ALVES-MAZZOTTI, Alda Judith; GEWANDSZAJDER, Fernando. O método nas ciências naturais e sociais. 2 ed. São Paulo: Pioneira, p.179-188, 1999.

AMIGUES, R. Trabalho do professor e trabalho de ensino. In: MACHADO, A. R. O ensino como trabalho - uma abordagem discursiva. Londrina: Editora da Universidade Estadual de Londrina, 2004 ARANHA, A. V. S. O conhecimento tácito e a qualificação do trabalhador. In Revista Trabalho e Educação. Belo Horizonte-MG: No. 2, p. 12-30, 1997.

DURRIVE, L. (2011). A atividade humana, simultaneamente intelectual e vital: esclarecimentos complementares de Pierre Pastré e Yves Schwartz. Revista Trabalho, Educação e Saúde, Rio de Janeiro, 9(1), 47-67.

FERREIRA, N. S. C. A gestão enquanto instrumento para a construção e qualificação da educação. Disponível em: <http://www.google.com/search?=cache: scGHPcjyEJ: www.centror BR\&ct= clnk\&cd=3\&gl=BR>. Acesso em: 07 jul. de 2008 .

FLICK, U. . Introdução à pesquisa qualitativa (3a ed., J. E. Costa, Trad.). São Paulo: Artmed, 2009 (Obra original publicada em 1995).

MACEDO, Roberto Sidnei. Etnopesquisa crítica/etnopesquisa-formação. Brasilia:LiberLivro 2010. MARX, K.. O capital. Crítica da economia polítical. I, v. I e II. 12 ed. Rio de Janeiro:Editora Bertrand Brasil, 1994.

MARX, Karl. Manuscritos econômicos - filosóficos: textos filosóficos. Portugal: Edições 70, 1964, v. 22.

MINAYO, Maria Cecília de Sousa (Org.). Pesquisa social, teoria, método e criatividade. Petrópolis: Vozes, 2001.

SCHWARTZ, Y. (2004). Circulações, dramáticas, eficácias da atividade indus triosa. Revista Trabalho, Educação \& Saúde, Rio de Janeiro, 2(1), 33-35.

TRINQUET, P. Trabalho e Educação: o método ergológico. Revista HISTEDBR, Campinas, v. 10, n. número especial, p. 93-113, ago. 2010

i Professor da UNEB - Campus XII Mestre em Educação Física-UNB e Doutorando em Educação -

FAE/UFMG. E-mail: jorge_adilson@yahoo.com.br

ii Professora titular da FAE/UFMG e Pós-doutorado pela UERJ. 